\title{
"SPILLOVERS FROM THE UNITED STATES TO LATIN AMERICAN AND G7 STOCK MARKETS: A VAR QUANTILE ANALYSIS"
}

Helena Chuliá, Montserrat Guillén and Jorge M. Uribe 


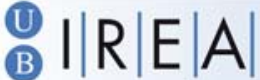

Institut de Recerca en Economia Aplicada Regional i Pública

Research Institute of Applied Economics

Universitat de Barcelona

Av. Diagonal, $690 \cdot 08034$ Barcelona

WEBSITE: www.ub.edu/irea/•CONTACT: irea@ub.edu

The Research Institute of Applied Economics (IREA) in Barcelona was founded in 2005, as a research institute in applied economics. Three consolidated research groups make up the institute: AQR, RISK and GiM, and a large number of members are involved in the Institute. IREA focuses on four priority lines of investigation: (i) the quantitative study of regional and urban economic activity and analysis of regional and local economic policies, (ii) study of public economic activity in markets, particularly in the fields of empirical evaluation of privatization, the regulation and competition in the markets of public services using state of industrial economy, (iii) risk analysis in finance and insurance, and (iv) the development of micro and macro econometrics applied for the analysis of economic activity, particularly for quantitative evaluation of public policies.

IREA Working Papers often represent preliminary work and are circulated to encourage discussion. Citation of such a paper should account for its provisional character. For that reason, IREA Working Papers may not be reproduced or distributed without the written consent of the author. A revised version may be available directly from the author.

Any opinions expressed here are those of the author(s) and not those of IREA. Research published in this series may include views on policy, but the institute itself takes no institutional policy positions. 
We estimate multivariate quantile models to measure the responses of the six main Latin American (LA) stock markets to a shock in the United States (US) stock index. We compare the regional responses with those of seven developed markets. In general, we document weaker tailcodependences between the US and LA than those between the US and the mature markets. Our results suggest possible diversification strategies that could be exploited by investing in Latin America following a sizable shock to the US market. We also document asymmetrical responses to the shocks depending on the conditioning quantile at which they are calculated.

JEL classification: F21; F30; G15

Keywords: International Spillovers, Quantile Regression, Emerging Markets, Stock Markets

Helena Chuliá: Riskcenter- IREA and Department of Econometrics, Universitat de Barcelona, Av. Diagonal, 690, 08034. Barcelona, Spain (hchulia@ub.edu ).

Montserrat Guillén: Riskcenter- IREA and Department of Econometrics, Universitat de Barcelona, Av. Diagonal, 690, 08034. Barcelona, Spain (ㅍuillen@ub.edu ).

Jorge M. Uribe: Department of Economics, Universidad del Valle, Calle 13, \#100-00, Ciudadela Universitaria Melendez, Cali, Colombia. (jorge.uribe@correounivalle.edu.co )

\section{Acknowledgements}

The authors thank the Spanish Ministry of Economy grant ECO2013-48326-C2-1-P, ECO2012-35584 and ICREA Academia. 


\section{Introduction}

The analysis of spillovers between cross-national stock market returns is of increasing interest in the empirical finance literature. A better understanding of the phenomenon is important for practitioners and policy makers alike since it can provide a sound basis for designing portfolio allocation, market diversification and hedging strategies, at the same time as highlighting market scenarios under which an actively guided monetary or macroprudential policy is likely to achieve the best outcomes in terms of preserving financial stability, for instance, in seeking to avoid international financial contagion.

However, research in the field has overwhelmingly focused on evaluating the effects of shocks on the first two conditional moments of return distributions, while ignoring other parts of the distributions. In this strand of the literature, studies analyzing stock market return spillovers, interdependence and contagion abound, which means a complete summary of this work would be impracticable in the scope of this paper. To name just a few, Becker et al. (1995), Bekaert et al. (2005), Bekaert et al. (2009), Jayasuriya (2011), Ehrmann et al. (2011), Bekaert et al. (2014) study the spillovers between the means of the return distributions, while other authors analyze the conditional variance spillovers to the mean (Bae et al., 2007; Diebold and Yilmaz, 2009; Beirne et al., 2010), and the pure volatility spillovers (Arouri et al., 2011; Rittler, 2011; Neaime, 2012; Lee, 2013). There are also many related studies that specifically test the existence of financial contagion, considering Latin American markets, following a significant shock to global financial markets (Bae et al., 2003; Chan-Lau et al., 2004; Marwat et al., 2009).

However, the above strategy does not appear completely justified on empirical grounds, because there seems to be a strong temporal dependence between the quantiles of the univariate distributions of financial returns, and not only between their second moments (Engle and Manganelli, 2004; Baur et al., 2012). Thus, it seems plausible to forecast a fuller range of the distribution using contemporaneous information, and our attention need not be restricted solely to the first two moments.

Quantile regression models constitute a promising tool for obtaining a better understanding of the way in which financial spillovers occur and for quantifying the sensitivity of different markets to international shocks. These models are known to be robust to outliers, which is particularly important for analyzing financial time series. They are also semiparametric in nature and, therefore, require minimal distributional assumptions on the underlying data generating process (DGP). Moreover, they offer greater flexibility for analyzing different market scenarios. For instance, while lower quantiles can be associated with bearish markets, higher quantiles are intuitively associated with bullish markets. Therefore, very high or very low quantiles can be expected to be related to other widely studied financial phenomena, such as bubbles, contagion or episodes of financial distress.

For the aforementioned reasons, it is not surprising, therefore, that quantile models have been incorporated into the financial literature. For instance, Basset and Chen (2001) use quantile regressions to study the way in which different portfolio styles (based on their sensitivity to certain market indexes) influence the whole distribution of the portfolios conditional returns, especially at the tail of this distribution. Engle and Manganelli (2004) 
use conditional quantile models to directly calculate Value at Risk statistics, instead of recovering them by estimating the conditional moments of a set of stock returns. Baur and Schulze (2005) analyze coexceedances in the markets, over specific thresholds, as they seek to identify episodes of financial contagion. $\mathrm{Li}$ and Miu (2010) employ a binary quantile model to examine predictions of bankruptcy employing market- and accounting-based factors.

More recently, Tsai (2012) documents a negative relationship between exchange rates and the stock price index in the highest and lowest quantiles of the distribution; however, the study does not provide evidence of a significant relationship between the variables in the quantiles near the median. Lee and $\mathrm{Li}$ (2012) document a non-linear diversification effect on firm performance, dependent on the quantile of the distribution. Ciner et al. (2013) use quantile regressions to explore whether the dependences between different asset classes in the US and the UK differ during episodes of extreme price movements. Gebka and Wohar (2013), using quantile regressions, document a strong non-linear causality in the highest and lowest quantiles of the series of volume and stock returns in the Pacific Basin countries. They also report a non-statistically significant relationship between volume and returns in the median of the distribution. Finally, Rubia and Sanchis-Marco (2013) analyze the predictability of different stock portfolios in the tails of the distribution, by using variables that proxy for market liquidity and trading conditions.

In common with any traditional regression, quantile models are susceptible to reverse causality, simultaneous equations, omitted variables, and, in general, to endogenous regressor considerations. Within the framework of cross-national spillovers, these concerns acquire particular relevance and so theoretical restrictions need to be identified before quantifying the relationship between markets in different quantiles of the returns distribution. Such restrictions can be very naturally imposed in the multivariate quantile setting proposed by White et al. (2015). Their framework can be thought of as a vector autoregressive (VAR) extension to quantile models, enabling the direct analysis of the degree of tail interdependence among different random variables.

In this paper we measure the response of the six main Latin American (LA) stock markets to a shock in the United States (US) stock index. We analyze the markets of Brazil, Chile, Mexico, Colombia, Argentina and Peru and we also report the results for six mature markets, for the sake of comparison (the United Kingdom, Germany, France, Canada, Italy and Japan). Unlike previous studies that make use of traditional quantile regressions to analyze dependence or spillovers between markets (Mensi et al., 2014) ${ }^{1}$, we use the multivariate quantile model proposed by White at al. (2015). This model has an additional advantage over reduced form models that analyze dependence in a broader sense than the traditional regression framework, using, for example, copula functions (Aloui et al., 2011). Namely, it allows the direct tracing of structural shocks from the US to the other markets, through the estimation of different quantiles of the multivariate distribution of market returns and by imposing minimal theoretical restrictions on the multivariate DGP describing the data. By so doing, we are able to compute pseudo impulse-response functions (PIRFs) during different market scenarios, and to document facts about the

1 These authors study the impact of shocks on the BRICs' markets. 
persistence and dynamics of the system after facing a shock conditional on the quantiles of the returns distribution.

In short, this study contributes to studies of contagion, market integration and cross-border spillovers during both regular and crisis episodes by applying multivariate quantile analysis to solve traditional problems in finance. Most of the studies in this branch do not consider specific quantiles of the distributions and, therefore, they do not condition their results to specific market situations. Instead, they focus on the mean of the distributions, which could underestimate the real effects of an international shock. Even traditional quantile studies do not make any attempt to identify structural shocks by recourse to theory, nor are they able to analyze certain features of the shocks, such as their persistence, during different market scenarios.

We focus our analysis on Latin American stock markets, which have been characterized by a highly positive dynamic in recent decades, in terms of market capitalization and liquidity ratios, after a far-reaching process of market liberalization and reforms to pension funds across the continent during the 80s and 90s (Gill et al., 2005; De la Torre et al., 2007). Moreover, the global financial crisis between 2007 and 2010 appears to have fostered financial flows into LA markets, as capital investors looked for diversification opportunities outside the mature markets, and as liquidity began to flourish around the globe, following persistently low market interest rates in the major economies.

Thus, between 2005 and 2014, the combined domestic market capitalization, reported on the webpage of the World Federation of Exchanges, of the markets in Buenos Aires, Sao Paolo, Santiago, Bogota, Mexico City and Lima, rose by almost a hundred per cent, climbing from USD 972.50 billion to USD 1,843.11 billion, in less than ten years. The indicator peaked in 2010 at USD 2717.47 billion, when global financial conditions began to be regularized, primarily in the US. After 2010, a marked fall was recorded in the indicators of the regional markets, especially in the largest, that of Brazil, which represents around a half of the total. In all likelihood this can be attributed to flight-to-quality scenarios and disparate expectations among investors in terms of the future of the emerging markets' economic fundamentals, for instance, in relation to commodity exports.

The dynamics of these regional markets is of interest, especially for institutional investors around the globe who are constantly looking for opportunities to diversify their portfolios. Moreover, a shock originating in the US market is of considerable interest for the LA economies given that the US economy is the destination of around $40 \%$ of the region's total exports and imports, making it by far the main commercial partner of LA countries ${ }^{2}$.

In general we documented smaller dependences between the LA markets and the US market than those between the US and the developed economies, especially in the highest and lowest quantiles. Nevertheless, we found an asymmetrical response to the shocks originating in the US market, depending on the conditioning quantile analyzed. This result holds regardless of whether the market under consideration is mature or emerging, an outcome that can be attributed to the phenomenon of flight-to-quality operating in the lowest quantiles (a positive shock in the US is followed by a negative reaction in the other

\footnotetext{
${ }^{2}$ Data taken from the webpage of the Comisión Económica para América Latina y el Caribe (CEPAL).
} 
markets), and a situation of liquidity spillovers between the markets in the highest quantiles (a positive shock in the US is followed by a positive reaction in the other markets).

Another useful way to understand our results is to consider the unconditional stock return distributions without focusing on any specific quantiles. In this case, a shock to the US market can be expected to flatten the distribution of financial returns in all other markets. This increases the likelihood of observing extreme returns in these markets in the period following the original shock. In other words, a shock to the US market will increase the Value at Risk (VaR) statistics associated with the other markets. However, this change is not symmetrical in the tails. For some countries, the right tail of the returns increases more than the left tail; for others, the situation is reversed. These results have obvious implications in terms of the optimal implementation of hedging strategies, portfolio diversification, and risk management, but also with regards to the optimal design of monetary and macroprudential policies.

The rest of the paper is organized as follows. First, we present a brief introduction to quantile modeling and the specific multivariate multiquantile MVMQ $(1,1)$ employed here. We then describe the data used to perform the estimations. The main results and discussion are presented in the next section. Finally, we outline the conclusions that can be drawn from this study.

\section{Methodology}

Since Koenker and Basset's (1978) seminal contribution, quantile models have been of growing interest in many fields of economics, being applied in disciplines that range from finance to macroeconomics and labor economics (Koenker, 2005). Quantile regression allows the researcher to study the relationship between economic variables not only at the center but also across the entire conditional distribution of the dependent variable. In traditional quantile regression, the quantiles of a dependent variable are assumed to be linearly dependent on a set of conditioning variables.

As in any structural modeling set up, causal relationships can only be identified after maintaining the exogeneity condition of the conditioning variables (Pearl, 2014; Heckman 2008). In a continuously integrating global financial market, this condition is difficult to assume in practice. Global investors can rapidly change their positions, by restructuring their portfolios. In turn, this has a feedback effect on global markets, breaking down the exogeneity requirement. Therefore, in order to recover the effects of specific structural innovations over a given system of financial prices, it is necessary to resort to the traditional multivariate time series tools, such as structural vector autoregressions (Sims, 1980), which have been available in the literature for decades.

Multivariate quantile models (MVMQ) allow the researcher to perform this task. They were recently proposed by White et al. (2015) as a multivariate extension of the influential CAViaR model developed by Engle and Maganelli (2004). The authors use an MVMQ $(1,1)$ model to analyze the sensitivity of financial institutions to systemic shocks (a market index constructed as a common factor of financial institutions' returns). This allows them to construct a measure of the performance of each financial institution facing financial distress (with a specific focus on the low quantiles). The general idea behind MVMQ models is that the quantiles of the distribution of a time series $r_{t}$ potentially depend on its own lags and on 
the lags of certain covariates of interest. Specifically, the MVMQ $(1,1)$ model employed in this study is given by the following two equations:

$$
\begin{aligned}
& q_{1 t}=c_{1}(\theta)+a_{11}(\theta)\left|r_{1 t-1}\right|+a_{12}(\theta)\left|r_{2 t-1}\right|+b_{11}(\theta) q_{1 t-1}+b_{12}(\theta) q_{2 t-1}, \\
& q_{2 t}=c_{2}(\theta)+a_{21}(\theta)\left|r_{1 t-1}\right|+a_{22}(\theta)\left|r_{2 t-1}\right|+b_{21}(\theta) q_{1 t-1}+b_{22}(\theta) q_{2 t-1},
\end{aligned}
$$

or more compactly by:

$$
q_{t}=c+A\left|R_{t-1}\right|+B q_{t-1}
$$

where $q_{i t}$ is implicitly defined as $\operatorname{Pr}\left[r_{i t} \leq q_{i t} \mid \mathcal{F}_{t-1}\right]=\theta, i=1,2$. That is, quantiles of stock return series $r_{i t}$, at level $\theta$, depend on the first lag of the returns $R_{t-1}$, via the matrix $A$, and on the first lag of the quantiles in the bivariate system, via the matrix $B$. Notice that the elements in the main diagonal of $B$ measure the dependence of the quantiles on its own lags. In contrast, elements outside the main diagonal measure the tail codependence between the quantile series.

Assuming one suitable exogeneity restriction in the system, it is possible to recover the structural innovations and, therefore, to calculate quantile pseudo impulse-response functions as proposed by White et al. (2015). Here, we use the fact that the US market can be taken as the origin of recent major shocks to the global financial markets, as documented by Ehrmann et al. (2011) and also the fact that this market mainly reacts to its own news, given its significant size and liquidity (Ehrmann et al., 2011; Brazys et al., 2015). In this way, while we impose the restriction that the US index is contemporaneously insensitive to external shocks, every other market reacts contemporaneously to the US index. This assumption remains a plausible and simple alternative in all cases, supported by the empirical literature, and it is much more suitable than assuming strict exogeneity of the global factors.

Pseudo impulse-response functions (PIRFs) differ from traditional functions because, unlike the latter where a one-off intervention $\delta$ is given to the error term $\varepsilon_{t}$, PIRFs assume that the one-off intervention $\delta$ is given to the observable return $r_{t}$ only at time $t$. At all other times there is no change in $r_{t}$. In this way, the pseudo $\theta$ th quantile impulse-response function for the ith return $r_{i t}$ is defined as:

$$
\Delta_{i, s}\left(\tilde{r}_{i t}\right)=\tilde{q}_{i, t+s}-q_{i, t+s}, \quad s=1,2,3 \ldots T
$$

where $\tilde{q}_{i, t+s}$ is the $\theta$ th-conditional quantile of the treated series, $\tilde{r}_{i t}$, and $q_{i, t+s}$ is $\theta$ thconditional quantile of the contra-factual series, $r_{i t}$. One advantage of PIRFs $\Delta_{i, s}\left(\tilde{r}_{i t}\right)$ is that they retain the traditional interpretation of IRFs, even when they can be calculated for different quantiles of the distribution. In this way, they allow us to enhance the analysis of extreme codependences between pairs of time series, approaching the problem of 
estimating tail dependences in a direct fashion, instead of indirectly, by recovering them using models of the first and second conditional moments.

\section{Data}

We used MSCI daily stock price indexes, as calculated by Morgan Stanley between 30 June 1995 and 30 June 2015, giving a total of 20 years of transactions (5218 observations). All data were obtained from Datastream International. The period was selected primarily on the basis of data availability for the whole sample. These indices measure the price behavior of the assets traded on the stock market in each country, without accounting for dividends. They are constructed in a standard way for each country, which allows market prices to be compared. We transformed the original prices into logarithmic returns by taking natural logs and differentiating.

In the case of Latin America, we used the country indexes of Argentina, Brazil, Chile, Colombia, and Peru, the largest, most liquid markets in the region. We selected the markets of the G7 economies as a benchmark, and so used the MSCI indicators for the United Kingdom, Canada, Germany, France, Italy and Japan. We also worked with the US index constructed by Morgan Stanley.

The period analyzed was marked by several crises, frequently preceded by boom-bubble episodes in the global financial markets. For instance, the period witnessed the Argentine debt crisis of 2002; the Colombian crisis of 1999; the last part of the Mexican crisis, known as the 'tequila crisis' in 1994-1995; the Asian crisis in 1997; the Russian crisis in 1998; the dotcom crisis in the US in 2000; the September 11 terrorist attacks; the global financial crisis from 2007 to 2009; and the European debt crisis in 2010, among others.

\section{Results and Discussion}

The events outlined above provided the motivation for our analysis of the time series quantiles. Reactions to the shocks originating in the main global financial market in periods of pronounced rallies are expected to differ markedly from those experienced during economic crashes. Reactions may also differ between periods of normal and extreme economic activity. All these episodes are naturally related to different quantiles of the market return distributions.

Below, we test the hypothesis of statistical dependence between the series of quantiles for the different markets, with the US index serving as a pivot point. First, we present the results of the reduced form vector autoregression (VAR), followed by the results for the pseudo impulse-response functions following a structural shock to the US index. Finally, we introduce various performance tests and robustness exercises.

\section{a. Reduced Form Vector Autoregression}

Tables 1 and 2 provide a summary of the estimated coefficients for the six main Latin American and the six mature markets in the reduced form model. We present the coefficients associated with Equation (2) that best describe the relationship of each index with the US indicator. The coefficients $a_{21}$ and $b_{21}$ were estimated at three different quantiles of the distribution of returns: $\theta=\{0.01,0.5,0.99\}$, for each country. We also 
report the joint statistical significance of the coefficients outside the main diagonal of the matrixes $A, B$, in each case.

We estimated bivariate VAR models between the US index and each of the twelve market indicators. Although this approach runs the risk of incurring bias due to omitted variables, it has the advantage of allowing us to use the PIRFs provided by White et al. (2015) in our analysis.

Table 1

Reduced form VAR coefficients at $50^{\text {th }}$ percentile

\begin{tabular}{|c|c|c|c|c|c|c|c|c|c|c|c|c|c|}
\hline \multicolumn{14}{|c|}{$50 \%$} \\
\hline & $c 2$ & $a 21$ & $a 22$ & b21 & b22 & js & & $c 2$ & $a 21$ & $a 22$ & b21 & $b 22$ & js \\
\hline \multirow[t]{2}{*}{ Argentina } & 0.00 & 0.00 & 0.01 & -0.08 & 0.08 & 0.54 & Canada & 0.00 & 0.00 & 0.00 & 0.00 & 0.00 & 0.01 \\
\hline & 0.04 & 0.02 & 0.01 & 0.70 & 0.76 & & & 0.00 & 0.00 & 0.00 & 0.70 & 1.20 & \\
\hline \multirow{2}{*}{ Brazil } & 0.00 & 0.00 & 0.01 & -0.03 & 0.00 & 0.33 & France & $0.09 * * *$ & 0.00 & 0.00 & -0.20 & $-0.94 * * *$ & 4.62 \\
\hline & 0.03 & 0.02 & 0.02 & 0.69 & 1.84 & & & 0.00 & 0.00 & 0.00 & 0.10 & 0.10 & \\
\hline \multirow[t]{2}{*}{ Chile } & 0.00 & 0.00 & 0.01 & -0.04 & 0.02 & 2.03 & Germany & $0.15^{* * *}$ & $-0.07 * * *$ & 0.0 & -1.5 & 0.1 & $17.73^{* * *}$ \\
\hline & 0.02 & 0.02 & 0.02 & 0.35 & 3.80 & & & 0.00 & 0.00 & 0.00 & 1.00 & 0.60 & \\
\hline \multirow[t]{2}{*}{ Colombia } & -0.01 & 0.00 & 0.03 & 0.10 & 0.03 & 0.07 & Italy & 0.00 & 0.00 & 0.00 & -0.30 & -0.40 & 1.85 \\
\hline & 0.02 & 0.01 & 0.02 & 0.40 & 0.44 & & & 0.00 & 0.00 & 0.00 & 0.40 & 0.60 & \\
\hline \multirow[t]{2}{*}{ Mexico } & 0.04 & -0.01 & 0.02 & 0.07 & $-0.78 * * *$ & 1.02 & Japan & 0.00 & 0.00 & 0.00 & 0.00 & 1.00 & 1.50 \\
\hline & 0.03 & 0.02 & 0.01 & 0.15 & 0.24 & & & 0.00 & 0.00 & 0.00 & 1.00 & 1.60 & \\
\hline \multirow[t]{2}{*}{ Peru } & 0.03 & 0.00 & 0.03 & -0.38 & -0.27 & 0.84 & UK & $0.08 * * *$ & $-0.07 * * *$ & 0.00 & -0.60 & $-0.50 * *$ & $10.74 * *$ \\
\hline & 0.03 & 0.02 & 0.02 & 0.51 & 0.66 & & & 0.00 & 0.00 & 0.00 & 0.40 & 0.30 & \\
\hline
\end{tabular}

Note: *** significant at $99 \%$, ** significant at $95 \%$, $*$ significant at $90 \%$. Reduced form VAR coefficients at $50^{\text {th }}$ percentile. $c 2$ is a constant, $b 22$ is the autoregressive quantile coefficient, $a 22$ is the autoregressive mean coefficient, $a 21$ and $b 21$ are the autoregressive cross-coefficients and $j s$ is the statistic associated to the joint significance of the cross-coefficients.

The statistics in Table 1 highlight certain similarities between the emerging and the advanced economies included in our sample. For instance, if we focus on the transmission of shocks between markets in the $50^{\text {th }}$ percentile (the median), we observe that the estimations of the cross-sectional effects, which relate the US market with the rest of the sample, tend to be non-significant. In the developed economies, only Germany and the United Kingdom show a negative and statistically significant coefficient $a_{21}$, as associated with Equation 2. The effects in the median, however, for the LA markets and the other mature economies are non-significant in all cases. The same result is found for the joint significance test (last column, Table 1).

The autoregressive coefficients, relating the median values with their own lags, are also insignificant in almost all cases (with the exceptions of France, Mexico and the UK). These results are consistent with the weak form of the efficient market hypothesis and support past evidence in the literature about the unpredictability of asset returns in the central fragment of the distribution, within a daily frequency framework (White, 2000; Christoffersen and Diebold, 2006). 
Table 2

Reduced form VAR coefficients at $1^{\text {st }}$ and $99^{\text {th }}$ percentiles

\begin{tabular}{|c|c|c|c|c|c|c|c|c|c|c|c|c|}
\hline & \multicolumn{6}{|c|}{$1 \%$} & \multicolumn{6}{|c|}{$99 \%$} \\
\hline & $c 2$ & $a 21$ & $a 22$ & b21 & b22 & js & $c 2$ & $a 21$ & $a 22$ & b21 & b22 & js \\
\hline \multicolumn{13}{|c|}{ Latin American Stock Markets } \\
\hline \multirow[t]{2}{*}{ Arg } & $-0.17 * *$ & $-0.16^{*}$ & -0.35 & -0.05 & $0.88 * * *$ & $17.71^{* * * *}$ & $0.20 *$ & 0.02 & $0.31^{* *}$ & 0 & $0.87 * * *$ & 5.28 \\
\hline & 0.1 & 0.11 & 0.19 & 0.03 & 0.05 & & 0.11 & 0.13 & 0.13 & 0.06 & 0.03 & \\
\hline \multirow[t]{2}{*}{ Bra } & $-0.18 * *$ & -0.14 & $-0.28 * *$ & -0.06 & $0.89 * * *$ & 6.08 & 0.05 & 0 & $0.24 * * *$ & 0.03 & $0.89 * * *$ & 0.94 \\
\hline & 0.11 & 0.2 & 0.12 & 0.05 & 0.05 & & 0.06 & 0.11 & 0.05 & 0.06 & 0.02 & \\
\hline \multirow[t]{2}{*}{ Chi } & $-0.12^{* *}$ & -0.08 & $-0.39 * * *$ & -0.04 & $0.86^{* * *}$ & 5.36 & 0.02 & 0 & $0.30 * * *$ & 0.03 & $0.87^{* * *}$ & 5.00 \\
\hline & 0.05 & 0.08 & 0.07 & 0.03 & 0.03 & & 0.03 & 0.07 & 0.06 & 0.02 & 0.03 & \\
\hline \multirow[t]{2}{*}{ Col } & $-0.27 * * *$ & -0.21 & $-0.58 * * *$ & $-0.08 * * *$ & $0.78 * * *$ & $18.52 * * *$ & $0.40 * * *$ & 0.08 & $0.80 * * *$ & 0 & $0.63 * * *$ & 4.68 \\
\hline & 0.06 & 0.15 & 0.09 & 0.03 & 0.03 & & 0.1 & 0.06 & 0.14 & 0.03 & 0.08 & \\
\hline \multirow[t]{2}{*}{ Mex } & -0.03 & -0.05 & $-0.09 * *$ & -0.01 & $0.96^{* * *}$ & 3.56 & 0.01 & $0.10^{* *}$ & $0.22 * * *$ & -0.03 & $0.93^{* * *}$ & 4.57 \\
\hline & 0.04 & 0.1 & 0.04 & 0.03 & 0.02 & & 0.02 & 0.05 & 0.06 & 0.02 & 0.02 & \\
\hline \multirow[t]{3}{*}{ Per } & $-0.08 * * *$ & -0.12 & $-0.27 * * *$ & -0.04 & $0.91 * * *$ & $15.36 * * *$ & $0.06 * * *$ & 0.06 & $0.15^{* * *}$ & -0.01 & $0.93 * * *$ & 3.64 \\
\hline & 0.02 & 0.08 & 0.08 & 0.03 & 0.03 & & 0.02 & 0.07 & 0.02 & 0.02 & 0.01 & \\
\hline & \multicolumn{12}{|c|}{ Mature G7 Stock Markets } \\
\hline \multirow[t]{2}{*}{ Can } & $-0.18^{* *}$ & -0.16 & $-0.34^{* *}$ & -0.05 & $0.88^{* * *}$ & $17.92^{* * *}$ & $0.21 *$ & 0 & $0.36^{* *}$ & 0.01 & $0.86^{* *}$ & 5.45 \\
\hline & 0.1 & 0.11 & 0.19 & 0.03 & 0.05 & & 0.12 & 0.15 & 0.18 & 0.07 & 0.05 & \\
\hline \multirow[t]{2}{*}{ Fra } & $-0.16^{* * *}$ & $-0.13^{* * *}$ & $-0.21 * * *$ & 0.01 & $0.85 * * *$ & $16.58 * * *$ & $0.07 * * *$ & $0.14 * * *$ & $0.29 * * *$ & -0.02 & $0.86^{* * *}$ & $27.32 * * *$ \\
\hline & 0.04 & 0.05 & 0.05 & 0.05 & 0.06 & & 0.03 & 0.04 & 0.03 & 0.02 & 0.03 & \\
\hline \multirow[t]{2}{*}{ Ger } & $-0.15^{* * *}$ & -0.12 & $-0.25 * * *$ & 0.03 & $0.83^{* * *}$ & $9.10 *$ & $0.04 *$ & $0.20 *$ & $0.14^{* * *}$ & -0.04 & $0.92 * * *$ & $12.44 * *$ \\
\hline & 0.05 & 0.07 & 0.05 & 0.02 & 0.04 & & 0.03 & 0.11 & 0.03 & 0.03 & 0.04 & \\
\hline \multirow[t]{2}{*}{ Ita } & -0.07 & -0.11 & -0.25 & -0.04 & $0.92 * * *$ & 7.48 & $0.07 * * *$ & 0.08 & $0.14^{* * *}$ & -0.02 & $0.94^{* * *}$ & 3.42 \\
\hline & 0.08 & 0.09 & 0.24 & 0.05 & 0.06 & & 0.03 & 0.08 & 0.02 & 0.03 & 0.01 & \\
\hline \multirow[t]{2}{*}{ Jap } & $-0.55 * * *$ & $-0.39 * * *$ & $-0.38 * * *$ & -0.03 & $0.65^{* * *}$ & $76.99 * * *$ & $0.09 * *$ & $0.35^{* * *}$ & $0.19 * * *$ & $-0.09 * * *$ & $0.89 * * *$ & $110 * * *$ \\
\hline & 0.13 & 0.05 & 0.09 & 0.05 & 0.09 & & 0.04 & 0.04 & 0.03 & 0.03 & 0.03 & \\
\hline \multirow[t]{2}{*}{ UK } & $-0.11^{* *}$ & $-0.22 * * *$ & $-0.19 * * *$ & 0.05 & $0.78 * * *$ & 77.66**** & $0.03^{* *}$ & $0.11^{* * *}$ & $0.11^{* * *}$ & -0.03 & $0.95^{* * *}$ & $21.77 * * *$ \\
\hline & 0.05 & 0.08 & 0.04 & 0.22 & 0.27 & & 0.01 & 0.04 & 0.02 & 0.02 & 0.02 & \\
\hline
\end{tabular}

Note: $* * *$ significant at $99 \%$, ** significant at $95 \%, *$ significant at $90 \%$. Reduced form VAR coefficients at $50^{\text {th }}$ percentile. $c 2$ is a constant, $b 22$ is the autoregressive quantile coefficient, $a 22$ is the autoregressive mean coefficient, $a 21$ and $b 21$ are the autoregressive cross-coefficients and $j s$ is the statistic associated to the joint significance of the cross-coefficients.

Another common pattern that can be documented at this stage of the analysis (Table 2) is the fact that tail-codependences appear to be more significant in the lowest quantile than they are in the highest one, independently of whether the market is mature or emerging. Indeed, 8 out of 12 markets present statistically significant cross-dependence at $\theta=0.01$ and only 4 out of 12 do so at $\theta=0.99$ (see joint test results in columns 7 and 12 ). In other 
words, shocks experienced by the US market tend to lengthen the tails of the return distributions in the other markets in an asymmetrical fashion. In a related study, Baur and Schulze (2005) analyzed 11 markets in Asia and four aggregate regional indexes in Europe, LA, Asia and the USA and similarly documented a stronger dependence between extreme negative returns than between extreme positive returns. However, these authors do not provide statistics for the dynamics of the system after a shock, nor do they undertake specific comparisons between LA markets and markets in rest of the world.

The similarities found in the median of the distributions of advanced and emerging markets contrast with the differences found in their highest and the lowest quantiles. Recall that high quantiles (i.e., $\theta=0.99$ ) are likely associated with bullish market episodes and financial bubble periods, in which sharp rates of growth in stock prices are recorded. In contrast, low quantiles (i.e., $\theta=0.01$ ) are mainly associated with bearish markets, periods of crises and scenarios of financial distress. These lower quantiles, when calculated at very low levels, such as $\theta=0.01,0.05$, can be interpreted as Value at Risk (VaR) statistics.

Bearing this in mind, Table 2 makes evident that at $\theta=0.99$ there is a greater codependence between the US and the mature markets than between the US and the LA markets. The joint hypothesis of quantile cross-dependence is maintained for Germany, the UK, France and Japan and it is rejected only in the cases of Canada and Italy.

If we examine the Latin American markets, a contrasting landscape emerges. In none of the six markets in our sample do we record a statistically significant cross-tail-codependence. Only Mexico exhibits an individually significant relationship in the case of the coefficient $a_{21}$. In all other instances, the autoregressive terms are statistically significant, but the codependence terms are not. This result indicates that there is a clear statistical dependence between the right tail of the marginal distributions in each market, but this dependence does not extend to the bivariate distribution. In other words, after a high-value realization in the returns of these markets, a high-value realization is expected to follow in the next period. However, this cannot be attributed to high (or low) realizations in the US market. This result contrasts with those recorded for most of the mature economies and is in line with previous findings in the literature that report a lower degree of financial interdependence between the LA and the global (and US) financial markets than that found with Western Europe markets (see Bekaert et al., 2005 and Bekaert et al., 2014).

It is also possible to analyze the left tail of the return distributions by inspecting the quantile in which $\theta$ equals 0.01 - that is, the 'Value at Risk' scenarios, the worst scenarios that can be expected during regular market conditions. Specifically, in $99 \%$ of occasions the returns are expected to be greater than the $1^{\text {st }}$ estimated percentile. In such cases, the evidence of tail-codependence between the US market and the other developed markets in the sample is decisive. Indeed, 5 out of 6 mature markets exhibit tail-codependence when we take the joint hypothesis statistic (Table 1) into account. Only in the case of Italy can the cross-dependence be disregarded. In the emerging Latin-American economies the evidence is more balanced. While tail-dependence is significant in the cases of Colombia, Peru and Argentina, it is not in those of Brazil, Chile and Mexico. This scenario is consistent with hypotheses forwarded in the literature that highlight the importance of amplifying mechanisms during crises, which induce contagion during episodes of financial distress. Although the argument has been made within a market (Brunnermeier and Oehmke, 2013), the same mechanisms could be operating at an international level. 


\section{b. Structural VAR - Pseudo impulse-response functions}

The analysis of the PIRFs at different quantiles substantiates the interpretation of the results above. We constructed PIRFs for each market, after identifying a structural shock as two standard deviations from the US index. Using the Cholesky factorization, we assume that the US is contemporaneously exogenous in each bivariate system.

The main results for the LA markets are presented in Figure 1 while Figure 2 shows the mature economy benchmarks. While the results are in line with the previous discussion, the PIRFs tend to be statistically significant in most cases with the exception of the central cases (associated with the medians of the distributions, which are not reported for reasons of space). These impulse-response functions have the advantage of allowing the observation of the time persistence of the shocks as well as the direction of the effects at each specific quantile.

An interesting trend clarified by observing the PIRFs is the fact that the two-standard deviation shock to the US market induces effects with opposite signs depending on the quantile. This observation holds in all cases, regardless of whether the market is mature or emerging. This means that a sizeable positive shock to the US index increases the probability of a very high or a very low observation in the other markets. Thus, a shock increases the highest and lowest quantiles by enlarging the whole support of the unconditional return distributions. In other words, conditioning on a specific quantile we find that, while in higher quantiles the shock produces a positive response, this is related to a negative effect in lower quantiles.

These results also present novel empirical evidence in favor of different trading strategies, depending on the location of an observed market realization among the quantile categories. Although it would be optimal to go long in developed or emerging markets in the highest quantiles, after a positive shock to the US market is observed, the strategy would be inappropriate in the lowest quantiles. Indeed, the opposite may well be the optimal course in such a scenario.

The methodology employed here also allows us to identify asymmetries in the size of the effects, and not just in the signs of the tails. For instance, Japan presents a clear case of asymmetry. Thus, while the shock reduces the $1^{\text {st }}$ percentile by 2.62 percentage points (pp), in the following 20 days it increases the $99^{\text {th }}$ percentile by $4.25 \mathrm{pp}$ in the same amount of time. This same pattern is documented in the case of Mexico (-3.57 pp in the left tail versus $5.56 \mathrm{pp}$ in the right tail); however, several markets present asymmetries in the other direction. That is, in the cases of Canada, Peru and Argentina the shock decreases the lowest quantiles by $-6.62 \mathrm{pp},-4.94 \mathrm{pp}$, and -6.60 , respectively, while it increases the highest quantiles by only $1.28 \mathrm{pp}, 3.54 \mathrm{pp}$ and $4.76 \mathrm{pp}$. 
Argentina

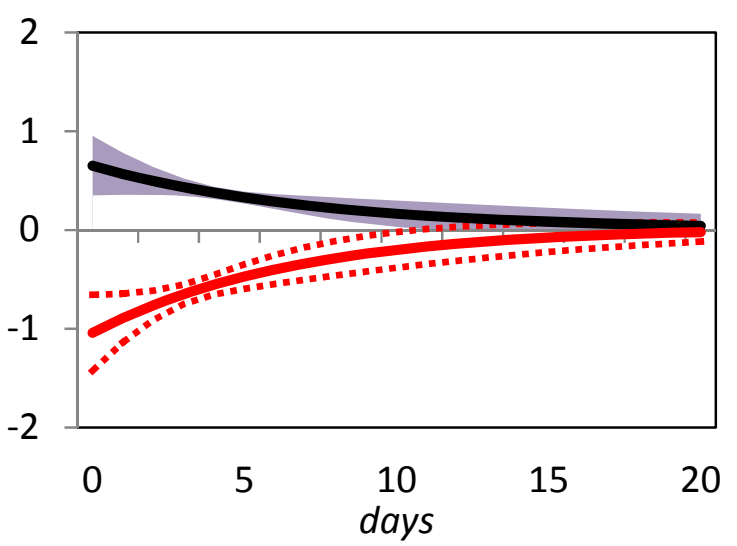

Chile

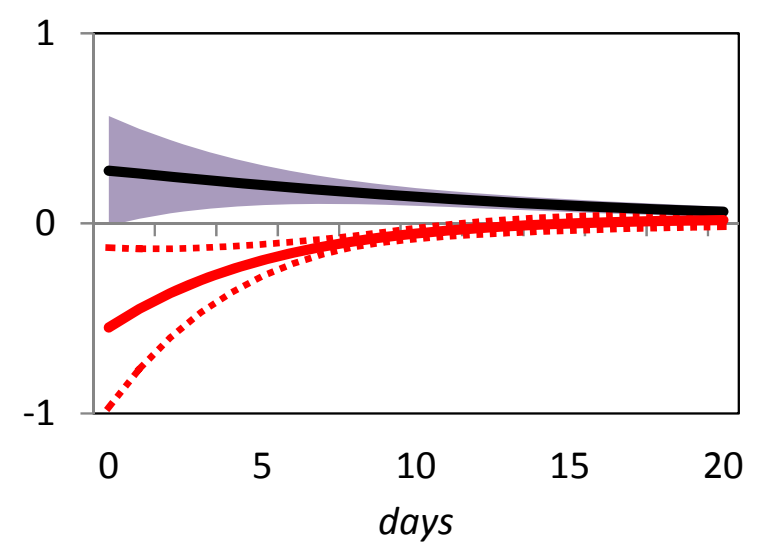

Mexico

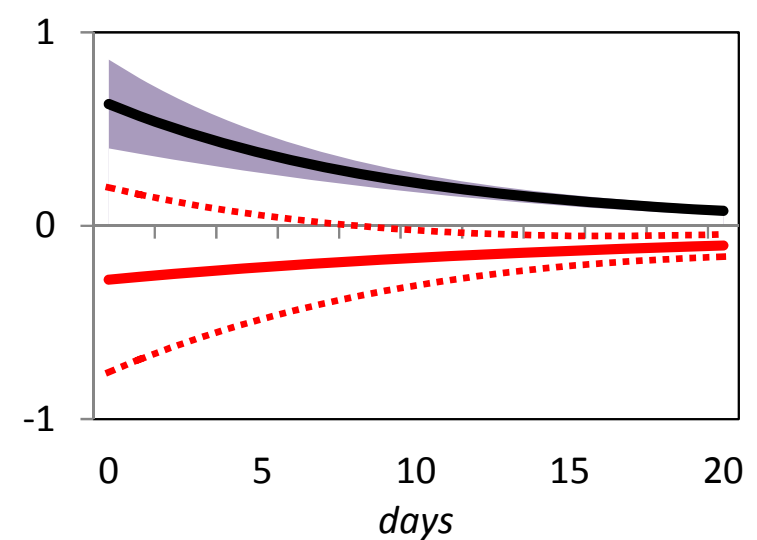

Brazil

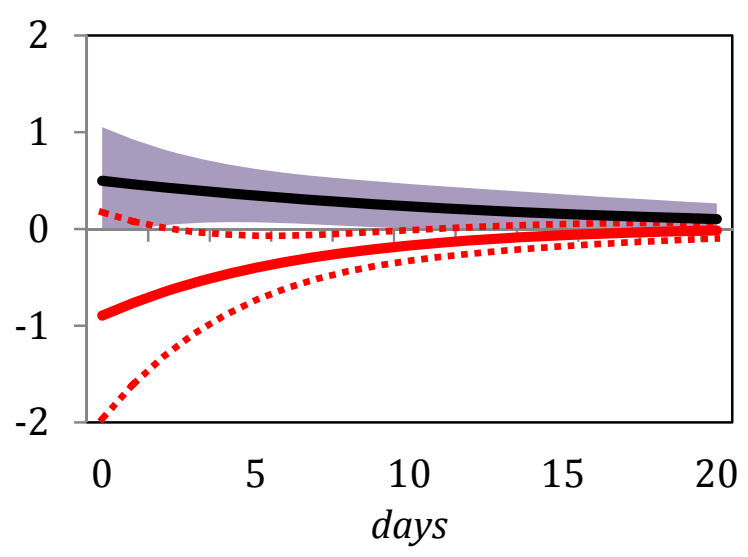

Colombia

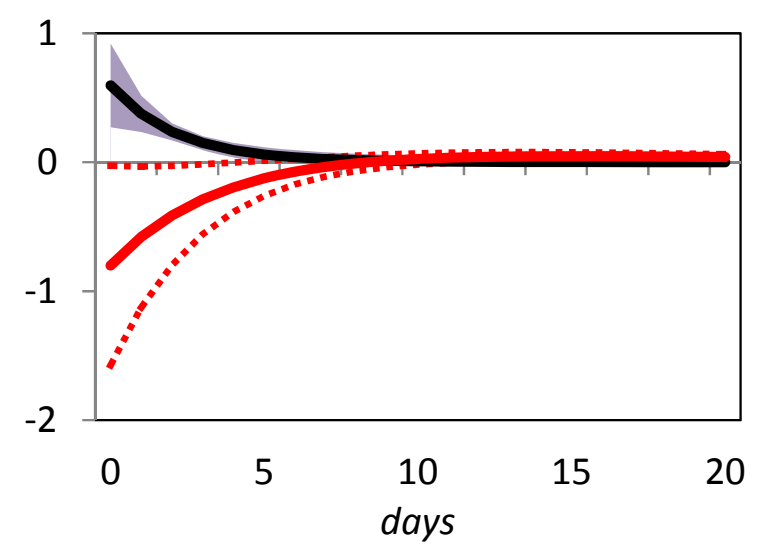

Peru

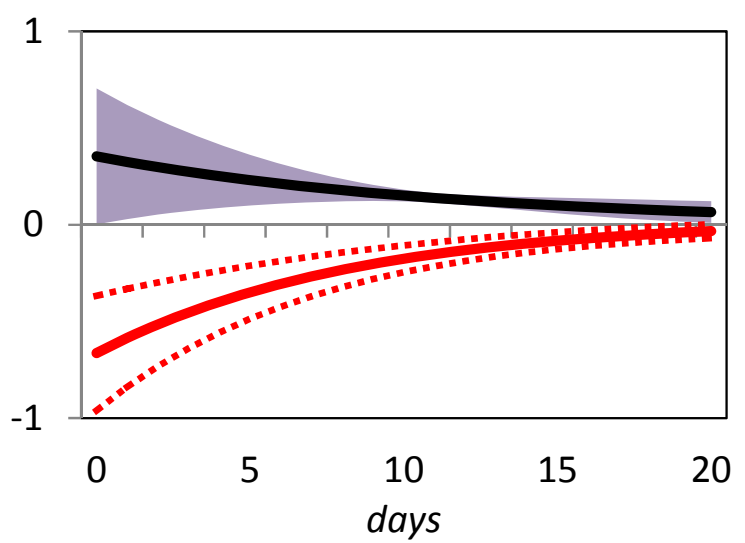

Note: The solid top line is the response at the $99^{\text {th }}$ percentile, and the corresponding $95 \%$ confidence interval is the shaded area. The solid lower line is the response at the $1^{\text {st }}$ percentile and the dotted lines are the corresponding confidence intervals.

Figure 1. Impulse-response functions of the LA markets to a two-standard deviation shock in the US market. 
Canada

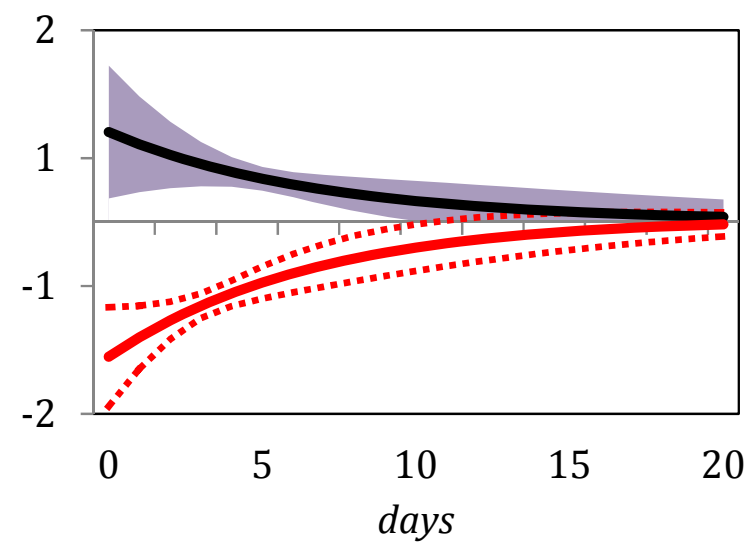

Germany

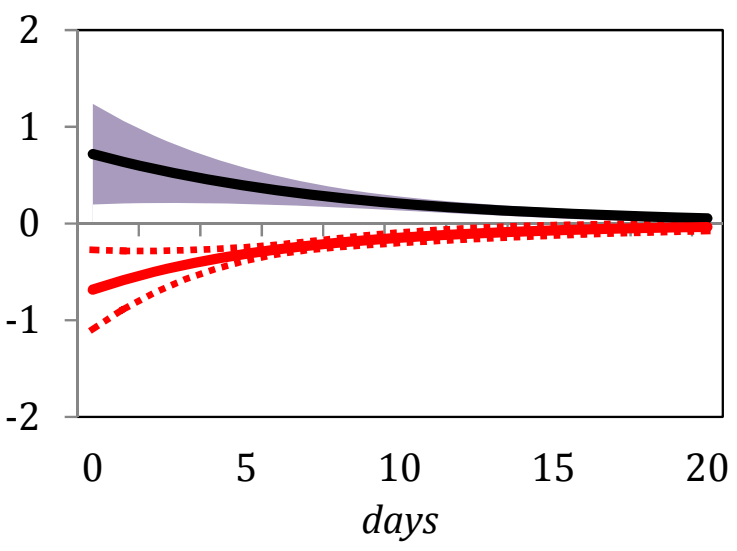

Japan

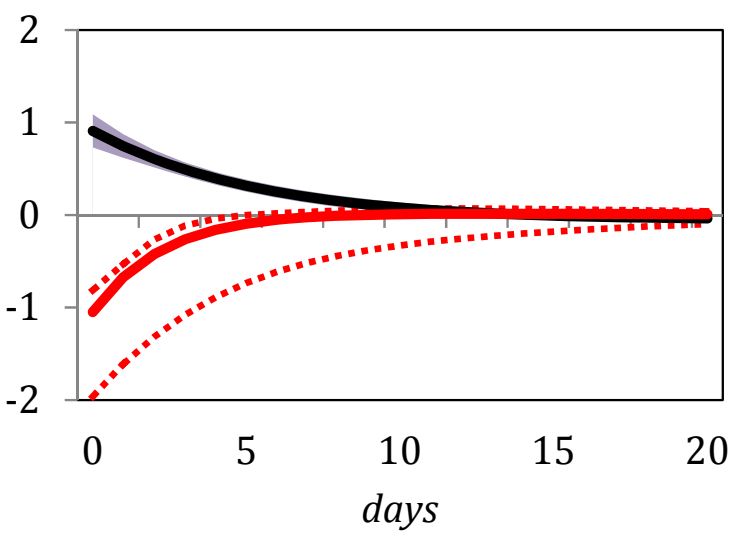

France

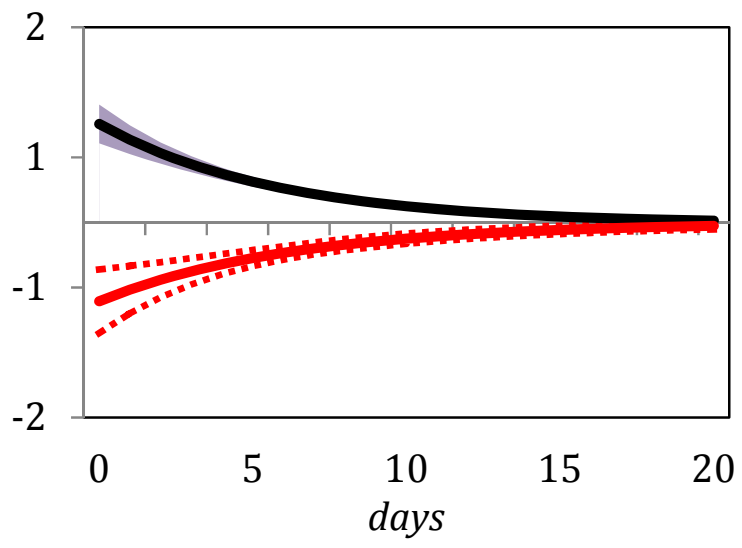

Italy

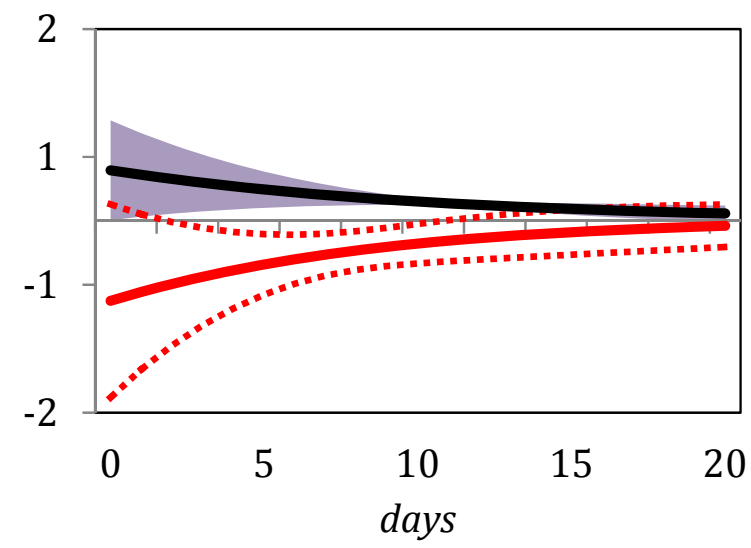

United Kingdom

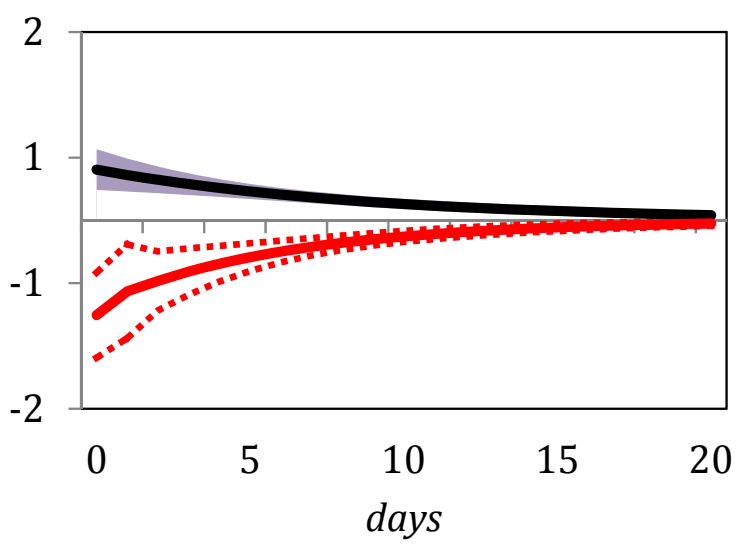

Note: The solid top line is the response at the 99th percentile, and the corresponding 95\% confidence interval is the shaded area. The solid lower line is the response at the 1st percentile and the dotted lines are the corresponding confidence intervals.

Figure 2. Impulse-response functions of the G7 markets to a two-standard deviation shock in the US market. 
The sign asymmetries documented in all markets can be related to episodes of flight-toquality in the lowest quantiles and possible liquidity spillovers in the highest quantiles. Flight-to-quality refers to an environment in which investors seek to sell assets that are perceived as risky and to purchase safe assets instead (Caballero and Kurlat, 2008). In a global financial market characterized by a very limited supply of financial instruments considered liquid by the international investors during episodes of financial distress, (Caballero et al. 2008), it is not surprising that a positive shock to the US market, which increments the VaR in the other markets, will be followed by flows in the direction of the central economy, which is considered less risky, by all standards.

On the other hand, although a liquidity spillover is sometimes referred to in the literature as a situation of illiquidity in one market that is transmitted to the other market, we use the term here to refer to an episode in which excess liquidity in one market (presumably that of the US) increases the liquidity in the other markets. The high liquidity increases the amount of trading and purchasing taking place in markets other than that of the US, as investors look for profitable opportunities around the world and seek to avoid abnormally low interest rates in US government-backed securities and other assets.

In short, at low quantiles following a positive shock to the US markets, capital prefers to migrate to this market, increasing the likelihood of a loss in the other markets; in contrast, at high quantiles, a positive shock to the US market possibly reflects greater liquidity in the global economy, which can potentially overshoot to other markets, especially the more highly developed markets, but to some extent also to those in the emerging economies. Thus, the statistic is a suitable tool for measuring contagion episodes driven by flight-toquality considerations or episodes of increasing correlation between markets, due to high liquidity levels in the global economy.

Note also that the differences in the responses are considerable within our sample, even within the Latin American zone. This points to the need for a careful analysis of the idiosyncrasies of each market before exploiting opportunities for diversification. For instance, Chile appears to represent a good opportunity for diversification most of the time: it does not present tail codependence in its high, median and low quantiles with the US markets, and the cumulated effect of the PIRFs is one of the smallest in the sample. In contrast, although Colombia, Peru and Argentina seem insensitive to the US market shocks in their highest quantiles, they are strongly affected in their lowest quantiles (financial distress episodes), which makes them less suitable locations for portfolio diversification during times of crisis.

Finally, regarding the persistence of the shocks in the markets, we first counted the number of days during which the shock remained statistically different from zero in each market. We then counted the number of days after which at least half of the shock's total impact (i.e., its half-life) had been absorbed (Table 3). In this way we can draw meaningful comparisons between the markets. Interestingly, the half-lives of the shocks in the LA and mature markets are very similar. The half-life median in bearish markets, both in mature and LA markets, is four days, while the half-life median in bullish markets is six days in emerging and five days in mature markets. In both cases there is a slight asymmetry, with the shocks being more persistent during positive extreme return scenarios than during negative extreme returns. On an individual basis, the market that houses the shortest persistence is Colombia, with two days in both tails (very similar in this respect to Japan). 
In contrast, Chile reaches nine days in the $99^{\text {th }}$ percentile and Mexico and Peru seven days, in the same tail.

Table 3

Persistence (half-life in days)

\begin{tabular}{|lcclcc|}
\hline & $\mathbf{1 \%}$ & $\mathbf{9 9 \%}$ & & $\mathbf{1 \%}$ & $\mathbf{9 9 \%}$ \\
\hline Argentina & 4 & 4 & Canada & 4 & 4 \\
Brazil & 3 & 4 & France & 5 & 4 \\
Chile & 3 & 9 & Germany & 4 & 5 \\
Colombia & 2 & 2 & Italy & 4 & 6 \\
Mexico & 9 & 7 & Japan & 2 & 3 \\
Peru & 5 & 7 & UK & 4 & 6 \\
\hline
\end{tabular}

Note: half-life of the shocks, in days, for different markets.

\section{c. Performance tests}

In this section we assess the overall performance of the models at $\theta=\{0.01,0.99\}$. This is possible by counting the number of exceedances of the actual returns above the highest quantile, and the number of exceedances below the lowest quantile. As usual, provided that we are constructing the quantiles at 1 and 99 per cent, we expect a number of exceedances in each case of around $1 \%$ of the times.

We present the returns of the markets and the estimated quantiles for the LA markets in Figure 3 and for the G7 markets in Figure 4. We also present the percentage of exceedances in Table 4.

As can be seen by visual inspection of the figures, and also by observation of the statistics in Table 4, the performance of the models appears to be highly satisfactory, both in the highest and lowest quantiles. We found percentages of exceedances in line with theoretical expectations for the selected confidence level, ranging from 0.98 to 1.02, with a mean value of 0.998 . 
Argentina

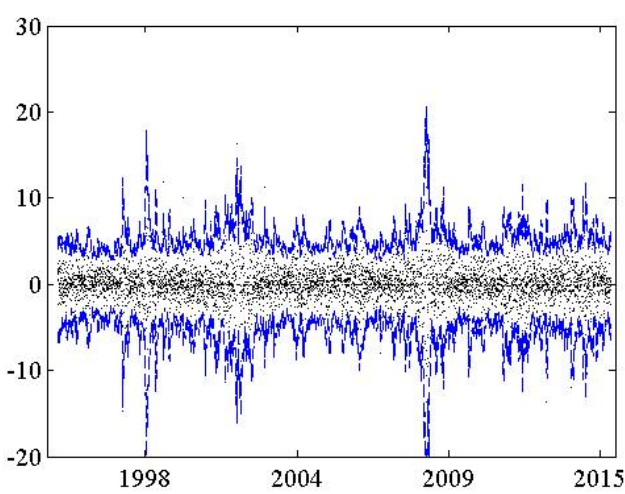

Chile

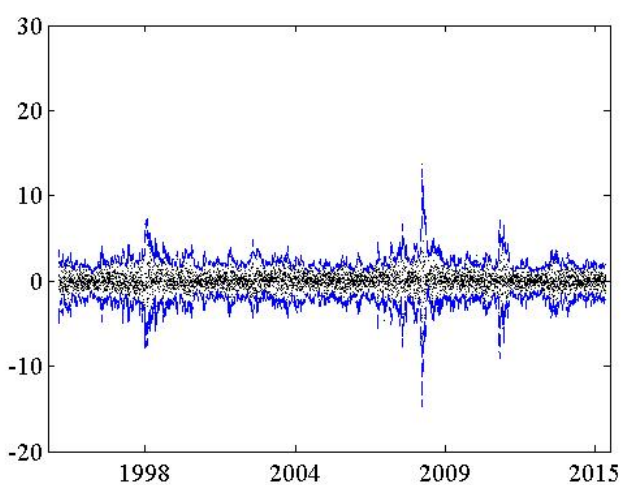

Mexico

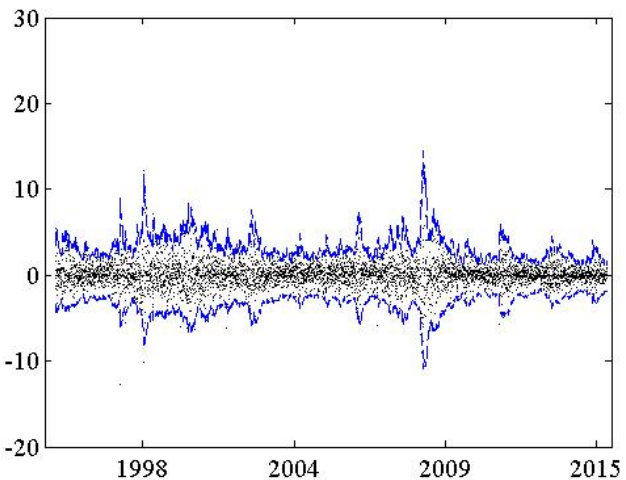

Brazil

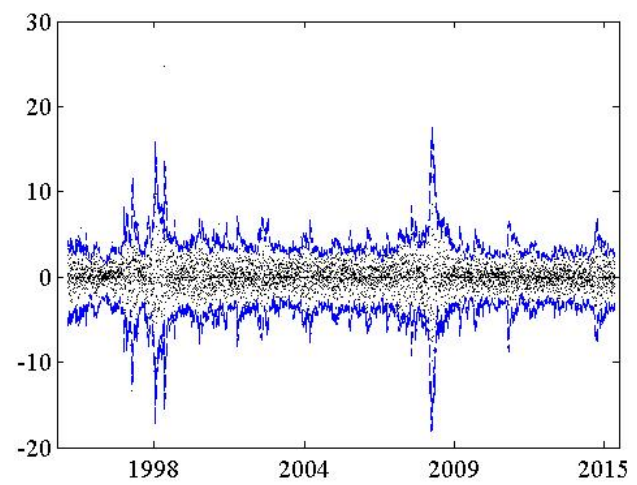

Colombia

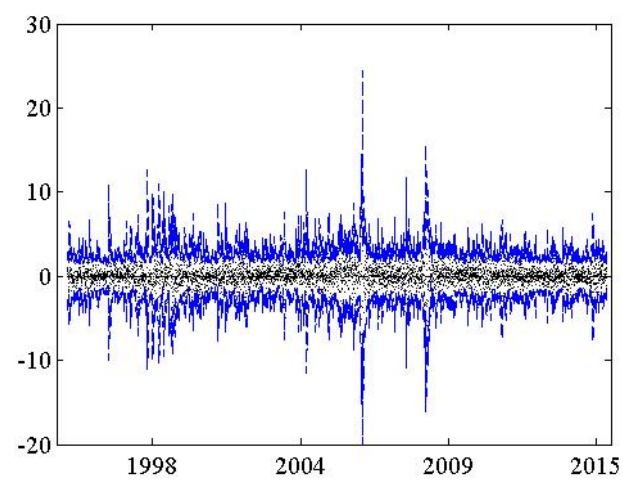

Peru

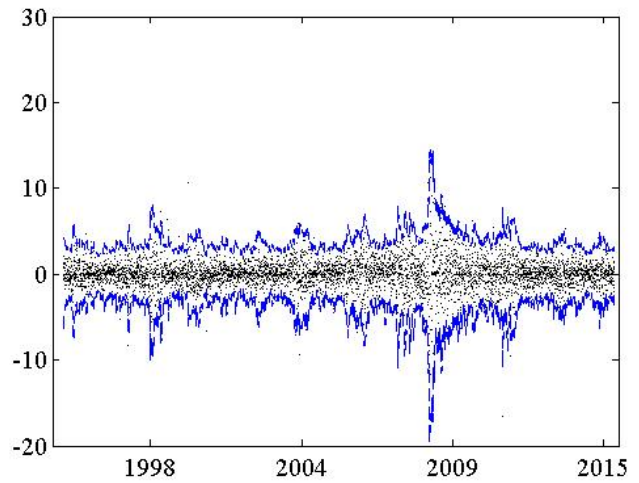

Figure 3. $1^{\text {st }}$ and $99^{\text {th }}$ percentiles and stock returns for Latin American markets.

Note: Time series of stock returns and quantiles at and 
Canada

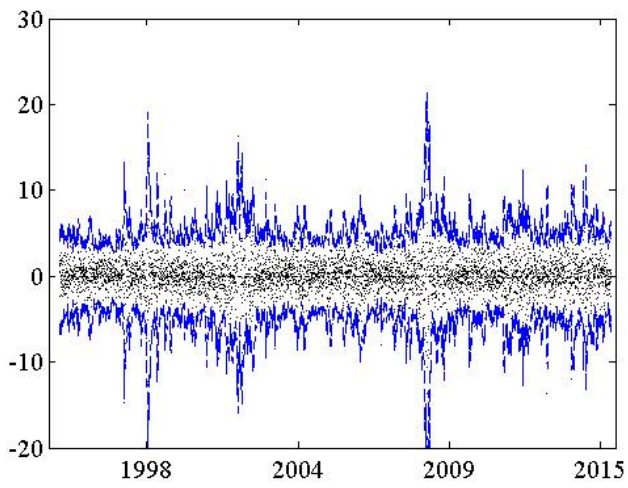

Germany

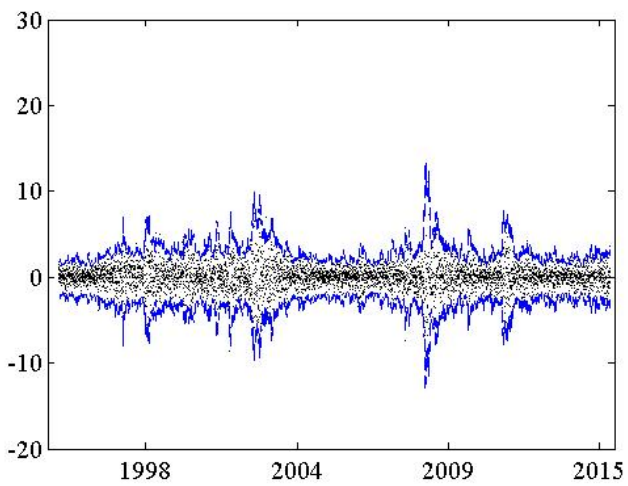

Japan

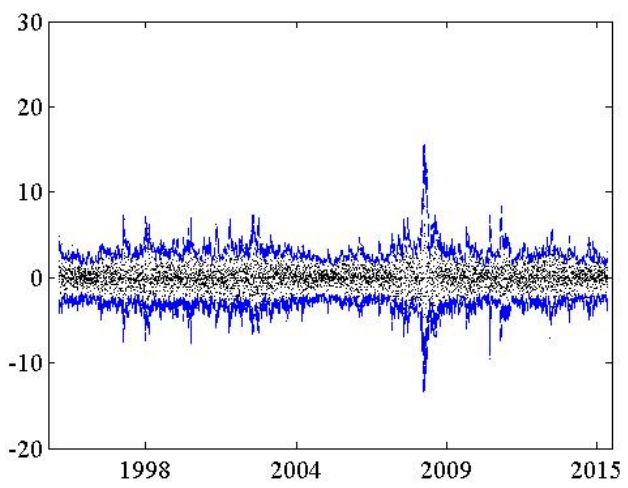

France

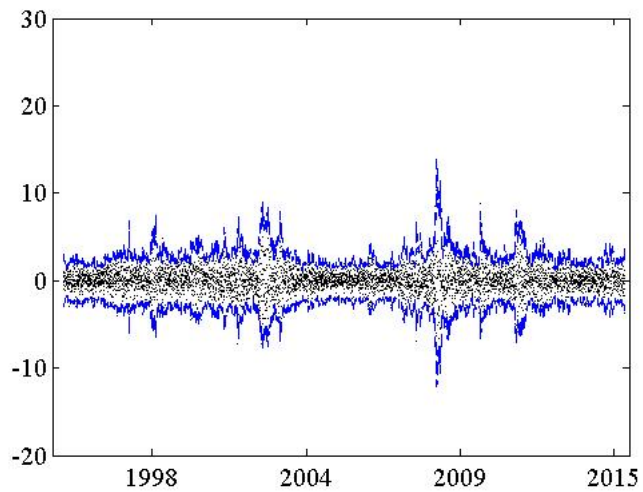

Italy

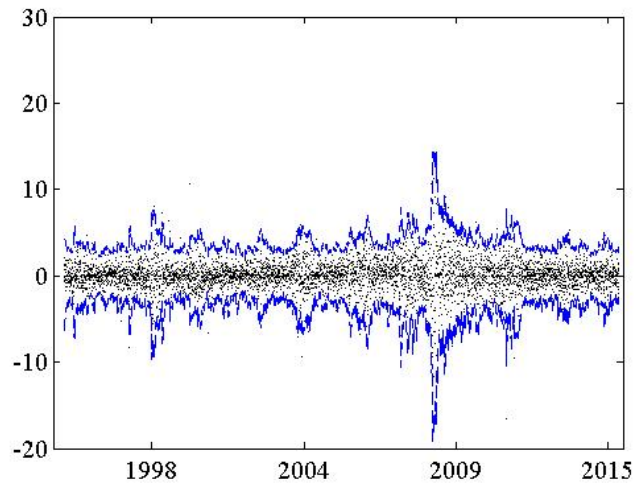

United Kingdom

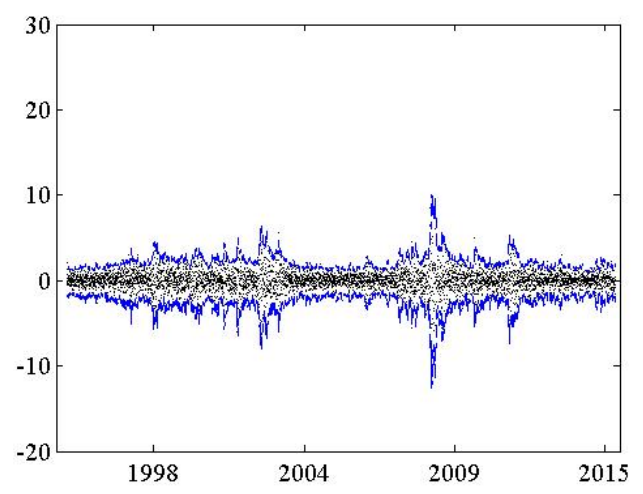

Figure $4.1^{\text {st }}$ and $99^{\text {th }}$ percentiles and stock returns for G7 markets

Note: Time series of stock returns and quantiles at and 
Table 4

Percentage of Exceedances

\begin{tabular}{|ccccccc|}
\hline & $\mathbf{1 \%}$ & $\mathbf{9 9 \%}$ & & $\mathbf{1 \%}$ & $\mathbf{9 9 \%}$ \\
\hline Argentina & 1.00 & 1.00 & Canada & 1.00 & 0.98 \\
Brazil & 1.02 & 1.02 & France & 1.00 & 1.00 \\
Chile & 1.02 & 1.00 & Germany & 1.00 & 1.00 \\
Colombia & 0.98 & 1.02 & Italy & 0.98 & 1.00 \\
Mexico & 0.98 & 1.02 & Japan & 1.02 & 1.00 \\
Peru & 0.98 & 0.98 & UK & 1.02 & 1.00 \\
& & & & & & \\
\hline
\end{tabular}

Note: Percentage of exceedances of stock returns above percentile $99^{\text {th }}$ and below the $1^{\text {st }}$ percentile. It is expected a percentage of exceedances similar to $1 \%$ in the two cases. The calculations highlight the accuracy in the construction of both the high and the low quantiles.

\section{Conclusions}

We document common and divergent patterns in reactions in LA and mature markets to a sizeable shock in US stock market returns. On the one hand, both the LA and mature markets in our sample show asymmetrical responses to the US market shock, dependent on the quantile analyzed. Following a positive shock in the US market, a positive effect is expected on the return distribution, provided the market is around the highest quantiles $(\theta=0.99)$. In contrast, at the lowest quantiles $(\theta=0.01)$, a positive shock to the US index produces a negative response in the other markets. We relate this first result to considerations of international liquidity overshooting, and the second to flight-to-quality effects among the US market and global financial markets.

A different interpretation is possible if we consider the unconditional distribution of the stock returns, without focusing on specific quantiles. In this case, what we find is that a positive shock to the US market is followed by a significant increase in the VaR statistics of the rest of the world sample, i.e., a risk increment. Nevertheless, the increments in the tails of the distributions follow irregular patterns, which depend on the idiosyncratic markets. For instance, while the increments in the right tail are higher for Japan and Mexico, the opposite is the case for Canada, Peru and Argentina.

Finally, we document a weaker tail-codependence among the LA markets in our sample than among the mature markets (except Italy) with respect to the US index, as indicated by both the coefficients of the reduced form VAR and the highest value of the PIRFs. This 
points to possible diversification strategies that could exploit investments in the LA markets following a shock to the US market.

However, the differences within the LA sample are notorious. While Chile and Brazil appear to represent good diversification strategies both in times of crisis and during economic rallies, Colombia, Peru and Mexico present higher tail-codependences during bearish scenarios than they do during bullish scenarios with regard to the US market. This makes them less suitable for diversification, especially during times of economic trouble, when diversification opportunities are more valuable for global investors.

In future research, it would be interesting to extend the cross-country comparisons performed here to include other emerging and developed economies. In this way, it would be possible to analyze global diversification strategies beyond the LA markets, using an endogenous multivariate setting. A further avenue for future research would be to incorporate more factors into the model structure, in addition to the US market index; however, this would require major extensions to the estimation process of the PIRFs and the MVMQ model, in general.

\section{Acknowledgements}

The authors thank the Spanish Ministry of Economy grant ECO2013-48326-C2-1-P, ECO2012-35584 and ICREA Academia.

\section{References}

Aloui, R., Ben-Aissa, M.S., Nguyen, D.K., 2011. Global financial crisis, extreme interdependences, and contagion effects: The role of economic structure? J. Bank. Financ. 35, 130-141. http://dx.doi.org/10.1016/j.jbankfin.2010.07.021

Arouri, M.E.H., Jouini, J., Nguyen, D.K., 2011. Volatility spillovers between oil prices and stock sector returns: implications for portfolio management. J. Int. Money Financ. 30, 1387-1405. http//dx.doi.org/10.1016/j.jimonfin.2011.07.008

Bae K-H, Karolyi A, Stulz R., 2003. A new approach to measuring financial contagion Rev. Financ. Stud. 16, 717-763. http//dx.doi.org/10.1093/rfs/hhg012

Bae, J., Kim, C.J., Nelson, C., 2007. Why are stock returns and volatility negatively correlated? J. Empir. Financ. 14, 41-58. http//dx.doi.org/10.1016/j.jempfin.2006.04.005

Bassett, G., Chen, H.-L., 2001. Portfolio style: return-based attribution using regression quantiles. Empir. Econ. 26, 293-305. http//dx.doi.org/10.1007/s001810100074

Baur, D., Schulze, N., 2005. Coexceedances in financial markets: a quantile regression analysis of contagion. Emerg. Mark. Rev. 6, 21-43. http//dx.doi.org/10.1016/j.ememar.2004.10.001

Baur, D.G., Dimpfl, T., Jung, R.C., 2012. Stock return autocorrelations revisited: a quantile regression approach. J. Empir. Financ. 19, 254-265. http//dx.doi.org/10.1016/j.jempfin.2011.12.002

Becker KG, Finnerty JE, Friedman J., 1995. Economic news and equity market linkages between the U.S. and U.K. J. Bank. Financ. 19, 1191-1210. http//dx.doi.org/10.1016/0378-4266(94)00079-I

Beirne, J., Caporale, G.M., Schulze-Ghattas, M., Spagnolo, N., 2010. Global and regional spillovers in emerging stock markets. A multivariate GARCH-in-mean analysis. Emerg. Mark. Rev. 11, 250-260. http//dx.doi.org/10.1016/j.ememar.2010.05.002

Bekaert G, Hodrick RJ, Zhang X., 2009. International stock return comovements. J. Financ. 64, 2591 - 2626. http//dx.doi.org/10.1111/j.1540-6261.2009.01512.x

Bekaert, G., Ehrmann, M., Fratzscher, M., Mehl, A., 2014. The global crisis and equity market contagion. J. Financ. 69, 2597-2649. http//dx.doi.org/10.1111/ji.12203 
Bekaert, G., Harvey, C., Ng, A., 2005. Market integration and contagion. J. Bus. 78, 39-69. http//dx.doi.org/10.3386/w9510

Brazys, J., Duyvesteyn, J., Martens, M., 2015. Macroeconomic news and price discovery in international bond markets. Presented in the European Financial Management Association, June 2015.

Brunnermeier, M., Oehmke, M., 2013. Bubbles, financial crises and systemic risk. In Constantinides, G.M., Harris, M. and Stulz, R. (Ed.) Handbook of the economics of finance 2B (2013), 1221-1288. Elsevier: Amsterdam. http//dx.doi.org/10.1016/B978-0-44-459406-8.00018-4

Caballero, R., Kurlat, P., 2008. Flight to quality and bailouts: Policy remarks and literature review. Massachusetts Institute of Technology, Department of Economics, working paper series. http://dx.doi.org/10.2139/ssrn.1297456

Caballero, R., Farhu, E., Gourinchas, P.O., 2008. Financial crash, commodity prices and global imbalances. Brook. Pap. Econ. Act. 1-55. http//dx.doi.org/10.3386/w14521

Chan-Lau, J., Mathieson, D., Yao, J., 2004. Extreme contagion in equity markets. IMF Staff. Pap. 51, 386408.

Christoffersen, P. F., Diebold, F. X., 2006. Financial asset returns, direction-of-change forecasting and volatility dynamics. Manag. Sci. 52, 1273-1287. http://dx.doi.org/10.1287/mnsc.1060.0520

Ciner, C., Gurdgiev, C., Lucey, B., 2013. Hedges and safe havens: an examination of stocks, bonds, gold, oil and exchange rates. Int. Rev. Financ. Anal. 29, 202-211. http//dx.doi.org/10.1016/j.irfa.2012.12.001

De la Torre, A., Gozzi, J.C., Schmukler, S., 2007. Stock market development under globalization: Whither the gains from reforms? J. Bank. Financ. 31, 1731-1754. http//dx.doi.org/10.1016/j.jbankfin.2006.11.008

Diebold F, Yilmaz K., 2009. Measuring financial asset return and volatility spillovers, with application to global equity markets. Econ. J. 119, 158-171. http//dx.doi.org/10.1111/j.1468-0297.2008.02208.x

Ehrmann, M., Fratzscher, M., Rigobon, R., 2011. Stocks, bonds, money markets and exchange rates: measuring international financial transmission. J. Appl. Econ. 26, 948-974. http//dx.doi.org/10.1002/jae.1173

Engle, R.F, Manganelli, S., 2004. CAViaR: Conditional autoregressive Value at Risk by regression quantiles. J. Bus. Econ. Stat. 22, 367-381. http//dx.doi.org/10.1198/073500104000000370

Gill, I., Packard, T., Yermo, J., 2005., Keeping the Promise of Old-Age Income Security in Latin America. Stanford University Press, Palo Alto, and the World Bank, Washington, DC.

Heckman, J., 2008. Econometric causality. Int. Stat. Rev. 76(1), 1-27. http//dx.doi.org/10.1111/j.17515823.2007.00024.x

Gebka, B., Wohar, M.E., 2013. Causality between trading volume and returns: evidence from quantile regressions. Int. Rev. Econ. Financ. 27, 144-159. http//dx.doi.org/10.1016/j.iref.2012.09.009

Jayasuriya, S., 2011. Stock market correlations between China and its emerging market neighbors. Emerg. Mark. Rev. 12, 418-431. http//dx.doi.org/10.1016/j.ememar.2011.06.005

Koenker, R., 2005. Quantile Regression. Cambridge University Press, Cambridge.

Koenker, R., Bassett, G., 1978. Regression quantiles. Econometrica 46, 33-50. http//dx.doi.org/10.2307/1913643

Lee, B.S., Li, M.Y.L., 2012. Diversification and risk-adjusted performance: a quantile regression approach. J. Bank. Financ. 36, 2157-2173. http//dx.doi.org/10.1016/j.jbankfin.2012.03.020

Lee, Y., 2013. Global and regional range-based volatility spillover effects. Emerg. Mark. Rev. 14, 1-10. http//dx.doi.org/10.1016/j.ememar.2012.09.007

Li, M.Y.L., Miu, P., 2010. A hybrid bankruptcy prediction model with dynamic loadings on accounting-ratiobased and market-based information: a binary quantile regression approach. . J. Empir. Financ. 17, 818833. http//dx.doi.org/10.1016/j.jempfin.2010.04.004

Markwat, T., Kole, E., Van Dijk, D., 2009. Contagion as a domino effect in global stock markets. J. Bank. Financ. 33, 1996-2012. http//dx.doi.org/10.1016/j.jbankfin.2009.05.008

Mensi, W., Hammoudeh, S., Reboredo, J.C., Nguyen, D. C., 2014. Do global factors impact BRICS stock markets? A quantile regression approach. Emerg. Mark. Rev. 19, 1-17. http//dx.doi.org/10.1016/j.ememar.2014.04.002

Neaime, S., 2012. The global financial crisis, financial linkages and correlations in returns and volatilities in emerging MENA stock markets. Emerg. Mark. Rev. 13, 268-282. http//dx.doi.org/10.1016/j.ememar.2012.01.006

Pearl, J., 2012. The causal foundations of structural equation modeling. In R. H. Hoyle (Ed.), Handbook of Structural Equation Modeling. Guilford Press: New York, (2012) Chapter 5, 68-91. 
Rittler, D., 2011. Price discovery and volatility spillovers in the European Union emissions trading scheme: a high-frequency analysis. J. Bank. Financ. 36, 74-785. http//dx.doi.org/10.1016/j.jbankfin.2011.09.009

Rubia, A., Sanchis-Marco, L., 2013. On downside risk predictability through liquidity and trading activity: a dynamic quantile approach. Int. J. http//dx.doi.org/10.1016/j.ijforecast.2012.09.001

Tsai, I.C., 2012. The relationship between stock price index and exchange rate in Asian markets: a quantile regression approach. J. Int. Financ. Mark. Inst. Money 22, 609-621. http//dx.doi.org/10.1016/j.intfin.2012.04.005

White, H., 2000. A reality check for data snooping. Econometrica 68, 1097-1126. http://dx.doi.org/10.1111/1468-0262.00152

White, H., Kim, T.H., Manganelli, S., 2015. VAR for VaR: Measuring tail dependence using multivariate regression quantiles. J. Econom. 187, 169-188. http//dx.doi.org/10.1016/j.jeconom.2015.02.004 


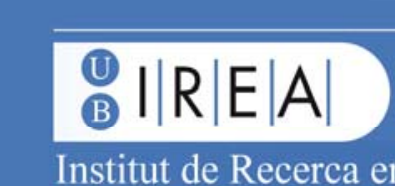

